\title{
Geopathogenic zones, mobile phones and their influence on human organism, animals and trees
}

\author{
Richard Kal'avský ${ }^{1}$, Silvia Duranková ${ }^{\mathbf{1}^{*}}$, Jarmila Bernasovská ${ }^{1}$ \\ ${ }^{1}$ Department of Biology, Faculty of Humanities and Natural Sciences, University of Prešov (FHPV UNIPO), Slovakia
}

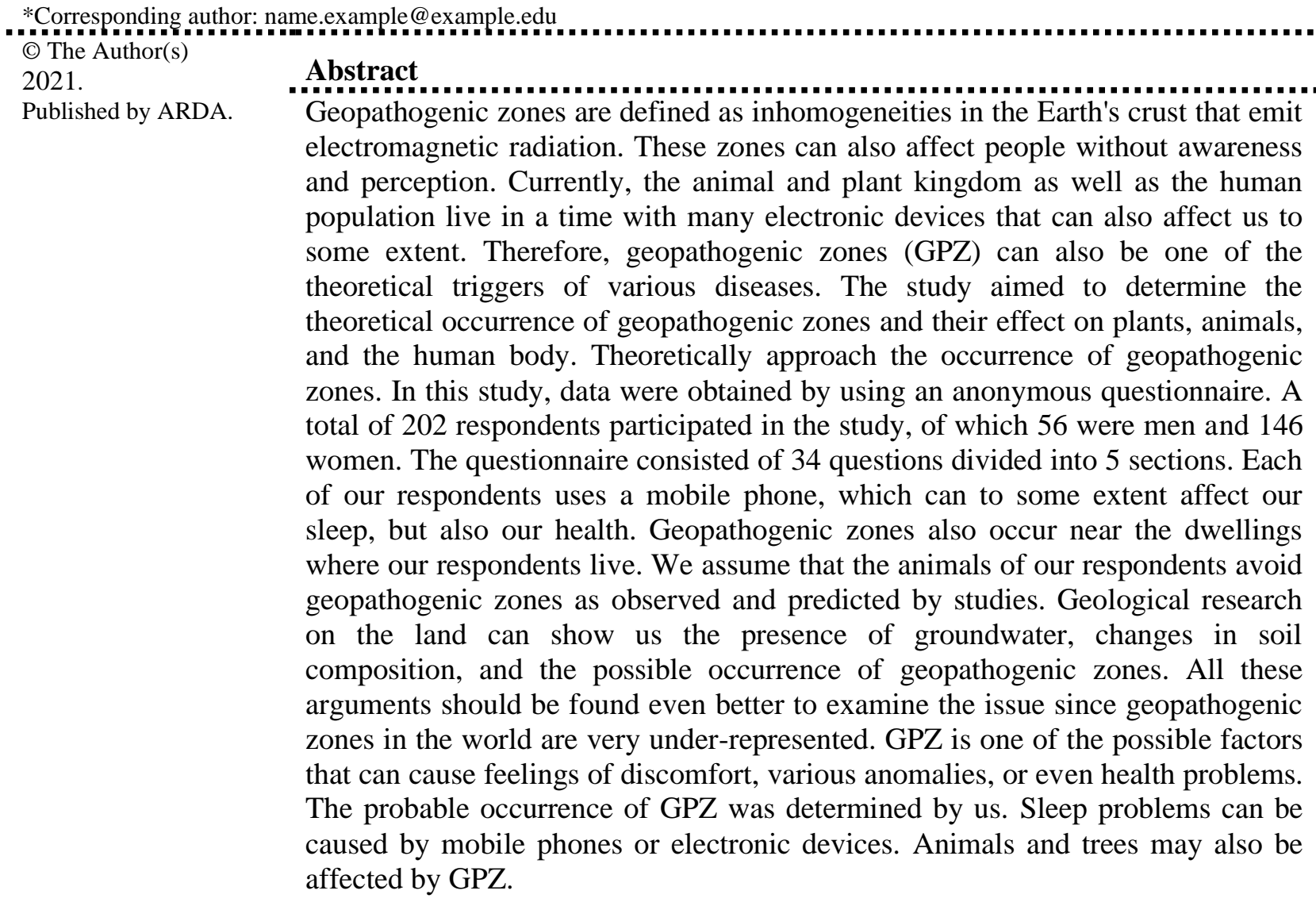

Keywords: Geopathogenic zones, Animal, Trees, Mobile phones, Human organism, Electromagnetic fields

\section{Introduction}

Effective and safe realization of the sea transportation, which is vital factor of the global economy, is of great importance. Stress may be responsible for a growing number of health problems. Geo-active environments such as the lithosphere, hydrosphere, etc. affect the health of the population. Just as geopathogenic zones or geopathic stress can cause health problems in humans, animals, and vegetation [1], [2]. Geopathic stress or geopathogenic zones (GPZ) has been known in one or another form in nearly all cultures and civilizations. The origin of the search for groundwater is lost in antiquity and especially absent in Greek and Roman manuscripts. Mentions of GPZ were also researchable in ancient times (1556) [3], [4]. The first written mentions of geopathogenic radiation date back to 2205-2197 BC. At that time, the Chinese Emperor Kung Yu issued a decree mentioning that no dwelling house may be built before the area will be

This work is licensed under a Creative Commons Attribution License (https://creativecommons.org/licenses/by/4.0/) that allows others (c) (†) to share and adapt the material for any purpose (even commercially), in any medium with an acknowledgement of the work's authorship and initial publication in this journal. 
examined by a prophet who does not declare that no "earthly spirits" are in place. Ancient civilizations respected certain localities, which they avoided when building dwellings [3], [5], [6]. The greatest contribution in this area was recorded in the years 1950 to 1960 by Ernst Hartmann, who discovered the Hartman's grid, and by Manfred Curry, the discoverer of Curry's grid [7]. They investigated inexplicably the reasons for the illness of different people who stayed and slept in the same place. No electronic devices were available at this time, so they used the dowsing method. Place where the 2-rays cross, Hartmann Knot and geopathogenic point was found. The crossing of two negative lines is repeated at approximately 35 meter intervals. Geopathic zones are characterized by variations in terrestrial magnetism, because the earth's field is not uniform but exhibits many highly localized distortions, some random, some fairly regular. These occur over geological faults, caves and underground water courses. [8], [9], [10]. In recent decades, the paradigm of GPZ has changed from a myth to a scientific reality thanks to the specialized work of independent groups of scientists from around the world. Ongoing studies have revealed that GPZ is often associated with groundwater and geo-errors. The correlation was proved between oncological diseases and the presence of geopathogenic zones [11], [12]. These zones are also associated with other diseases and so-called "black spots". These zones also affect certain sections of roads where there is an increased incidence of fatal accidents compared to other roads [11], [12], [13]. Magnetic and electromagnetic fields affect the human body; they interfere with the brain and affect the release of melatonin. Our mind, body and the function of our endocrine gland and immune system are controlled by extremely weak electrical brainwaves that interact with the electromagnetic environment. To influence the organism, the external energy source must come into interaction with the body, organs, cells, or organelles [5], [14], [15]. According to existing scientific documents, geopathogenic zones (GPZ) harmed the human body and were well known to an advanced civilization. Scientists, from different fields of activity, assume that there are more sources of radiation besides GPZ. Electromagnetic fields (EMF) are present everywhere around the world. Nowadays they are the subject of intensive worldwide research. The problem of GPZ is very difficult because of unclear mechanism and based on their origin [5], [14], [15], [16]. The main aim of the study was to find out and assess its impact on the health status of respondents based on the GPZ questionnaire. The main aim of our study was to point out the presence of GPZ as one of the factors that can influence people with a negative effect. This can influence not only humans, but also animals and flora. There is not much attention connected to this issue in the world. In our article, we intend theoretically to at least approach the consequence of GPZ, the influence of electromagnetic radiation and the formation of these zones. We asked our respondents where they charge their mobile phone or if they have sleeping trouble. How long they use the phone during the day. Subsequently, we evaluated the answers and determined the theoretical effect of electromagnetic radiation and the extent to which it can affect human health. We asked our respondents whether a geological survey was carried out on their land, so we can find out the occurrence of groundwater, various subsoil and these are the places where GPZ arises. We used an anonymous questionnaire to obtain our results.

\section{Material and methods}

The study involved 202 (56 men and 146 women) respondents who completed an anonymous questionnaire. The process of selecting participants was completely random, intended for the public, and accessed electronically. The questionnaire was not age restricted. The most relevant graphs were used in the results. The questionnaire was consisted of 34 questions, which were divided into 5 parts. The sections were focused on the interaction of electronic devices on the human body, the symptoms of GPZ. The last parts were focused on the problem of sleeping in the use of electronic devices and the interaction of GPZ on animals, plants, or trees. All results of the questionnaire were processed using the excel program and the relevant data were graphically processed and were presented in tables and graphs (Fig. 1-9). The analysis confirmed that the main group of our respondents were people aged 21 to 30. Also, this age group was the most suitable for our research, because they use many more electronic devices than, for example, pensioners, etc.

\section{Discussion and results}

Dubrov [17] and Stark [9] stated that the newly created technique that reveals GPZ on humans that was called the "Vegetative Resonance Test" (VRT). This technique was based on bio-resonance diagnostics of the human body. Animals, trees, or plants are very helpful in locating GPZ. They are a very good indicator of whether there are such zones on land or in households. 


\subsection{Mobile phone}

The use of a mobile phone was confirmed by all respondents (100\%), which was proof of everyday use. Although we did not take into account other electronic devices in our study, we assume that they are also located near their place of sleep. In total, up to $30 \%$ of our participants charge the phone near the bed which is close to the head (Fig. 1), and 29\% of them during the night. They still create electromagnetic fields (EMF). So electromagnetic waves can affect low-frequency brain waves [18], [19]. However, further research into these distortions is needed.
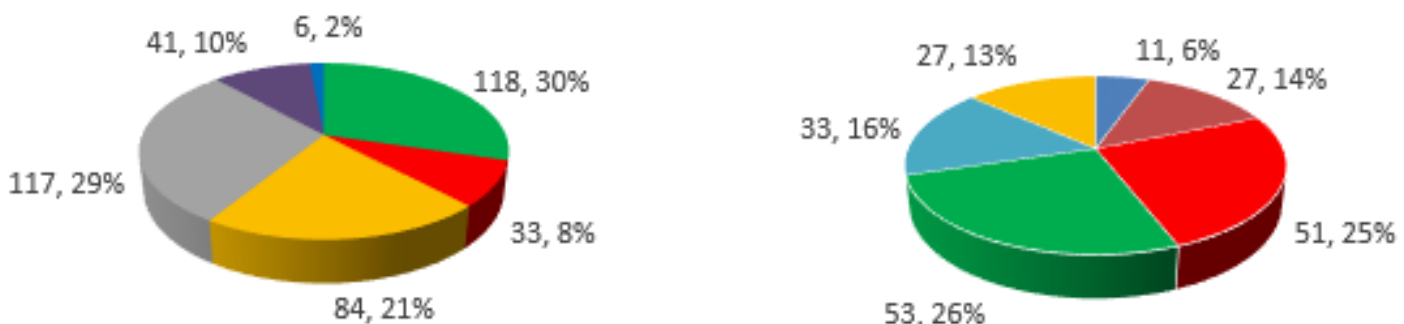

$53,26 \%$

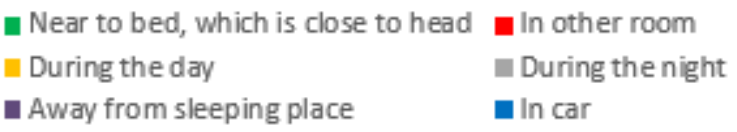

Figure 1. Phone position when charging

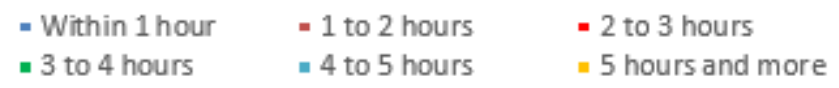

Figure 2. Average daily time of using a phone

The average time that our respondents spend using mobile phone is 3 to 4 hours per day (Fig. 2), that means $26 \%$. Respondents used other functions on phone also (e.g., wireless internet connection, GPS, etc.), spreaded by electromagnetic waves. In $38 \%$ of our cases, respondents never used their phone during the night. That is not good for our sleeping cycle.

\subsection{Sleep and electronic devices}

Mobile phones and other electronic devices can affect our sleep during the night. It was confirmed, that when a message was received, and display turn on the level of the hormone melatonin decreases. The human brain feels this decline and makes an adequate response. Subsequently, we wake up or sleep without going through all the sleep phases. Then we wake up sleepless or feel tired during the day or suffer from headaches etc. [19], [20], [21]. Melatonin, which is a hormone responsible for sleep, has an important role also. Melatonin is produced by the pineal gland and up to $80 \%$ is formed at night [23], [24]. However, in our survey, 73 respondents $(36 \%)$ have almost no problem with falling asleep (Fig. 3). Electronic devices have a great influence on the quality of our sleep. Sleeping and working continuously in a geopathogenic zone leads to emotional and physical troubles [25], [26]. From the data we obtained from our participants, we found out that most people have no problem falling asleep. There is no waking up during the night either. To increase the quality of sleep, we don't recommend using electrical equipment for at least 30 minutes before going to bed. Also do not leave your mobile phone under the pillow during the night, where there is a significant interaction with brain waves as mentioned above.

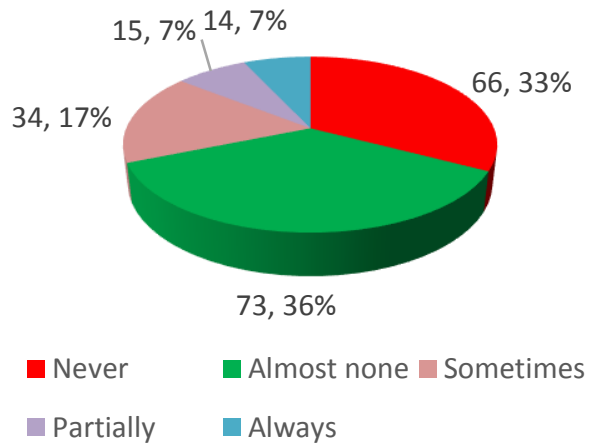

Figure 3. Problem with falling asleep 


\subsection{GPZ from the ground}

Living in a panel block in higher flats is better because there is a smaller area that can be affected by GPZ. However, when there is GPZ, it goes through several floors and can affect more people at once. In our cases, $37 \%$ of our respondents live in flats. If GPZ was located somewhere under the garden, animals and plants were mainly affected by these zones. Moreover, if there is a well in the garden there is a probability of groundwater occurring which is the source of GPZ [8], [27], [28]. In a house with a garden lived 63\% of our participants and the geological survey was conducted on 50\% of 173 respondents (Fig. 4). It confirmed that geological survey is a very good tool for confirming the GPZ and their influences.

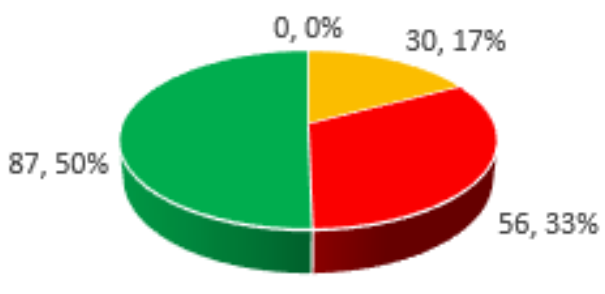

$$
\text { "Yes - No - I don't know }
$$

Figure 4. Has geological survey been carried out on your land?
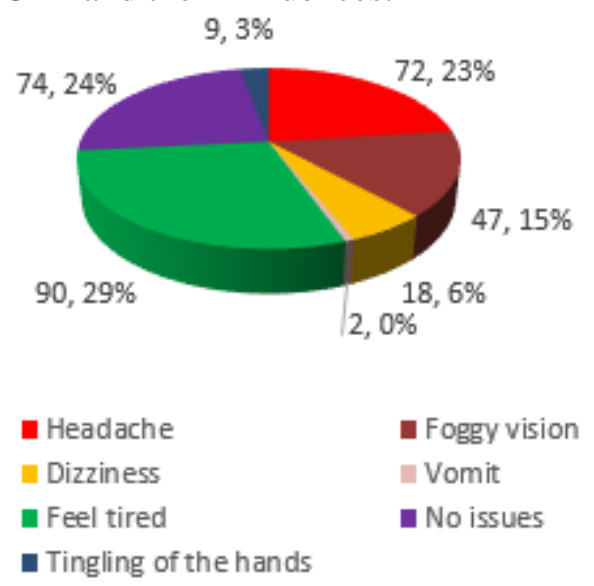

Figure 5. Health problems when using electronic devices

Excessive using a mobile phone can lead to health issues, also. For example, 29\% of respondents feel tired (Fig. 5) and $23 \%$ of them suffered from headache. If there is a strong and long-term interaction between human body and mobile phones, then there are worse health problems [6], [28]. Our research also showed that $15 \%$ of our respondents stated fog vision and $6 \%$ had also dizziness.

The unusual or unpleasant feeling may not only be caused by geopathogenic zones, but also by the interaction of the electromagnetic field with the human body. Geopathogenic zones are a primary factor influencing the health or sickness of our living or working environment. Energies from the earth at specific locations can change the normal functions of the human body as it generates harmful radiations and produce heat, which affects the human health. Many body processes are controlled electrically, including vital messages from the brain to the cells and an electrical impulse that maintains the heartbeat. Therefore, all body fluids are good electrical conductors [26], [28], [30]. In general, geopathogenic zones occur in places where there are different inhomogeneities in the earth's crust, or in different places where the soil composition changes, in old buried caves and also by the action of groundwater, as claimed by Aghav [26] and Krinker [13].

\subsection{Animals, trees and GPZ}

Very important point was having a pet, from which dogs dominated in 57\% of cases. Dogs were the best indicator to locate GPZ because they avoided these zones. They know how to sense negative radiation from the ground because this infrasound reminds them of a growl which is very unpleasant for them. In contrast, cats were the opposite of dogs, and only $18 \%$ of respondents owned a cat. They searched for GPZ because if they are in optimal conditions then they purr. Therefore, it is popular for cats to look for these zones which remind them of these infrasound zones [9], [14]. Animals, especially dogs, therefore tend to have a place where they are staying or sleeping or avoiding certain places such as the 60\% of cases in the survey GPZ [29]. These zones can be identified using trees or plants because GPZ causes various growth anomalies, various disorders in the nutritional system, or pathogenic growth on a tree trunk or other parts of the tree. Several, 
following photos showed these growth anomalies of the trees (Fig. 7-9). Animals or trees are a very good indicator of GPZ. In our survey, our respondents stated that their animal, most often it was a dog, has favorite places to sleep and places to avoid. The dog cannot sleep where he is irritated by infrasound, which reminds him of growling. The best place to put the bed is where the dog lies down to sleep. Geopathy does not influence humans only. Some plant and animal species are attracted to GPZ and may be an indication of its presence. Cats are very fond of it, as are insects generally, molds and fungi, and the number of medicinal herbs, including mistletoe. Trees are not properly grown up in stress zones [7], [26], [29], [30], [31]. Based on the results of our survey, we can say that the dogs of our respondents are definitely looking for places to sleep (Fig. 6), so we can assume that they avoid GPZ. Also, based on photographs, we see that the trees grow over GPZ therefore there is a growth anomaly but it would be necessary to conduct further measurements.

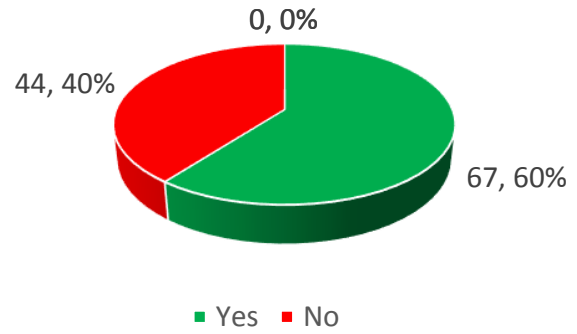

Figure 6. Does your pet have a favorite place to sleep?

We can see a tree growth anomaly (Fig. 7), which can be caused by GPZ. However, this anomaly may not be caused only by GPZ but also failures in the system of nourishment trees and many other errors. We can notice (Fig. 8) the crooked growth of the tree while behind them is a tree that grows perfectly fine. This tree may just be affected by GPZ that is causing this crooked growth. However, there can also be a malfunction in the tree's nutritional system. Fig. 9 shows us a pathogen on a tree trunk. Most likely this tree is located above the GPZ.

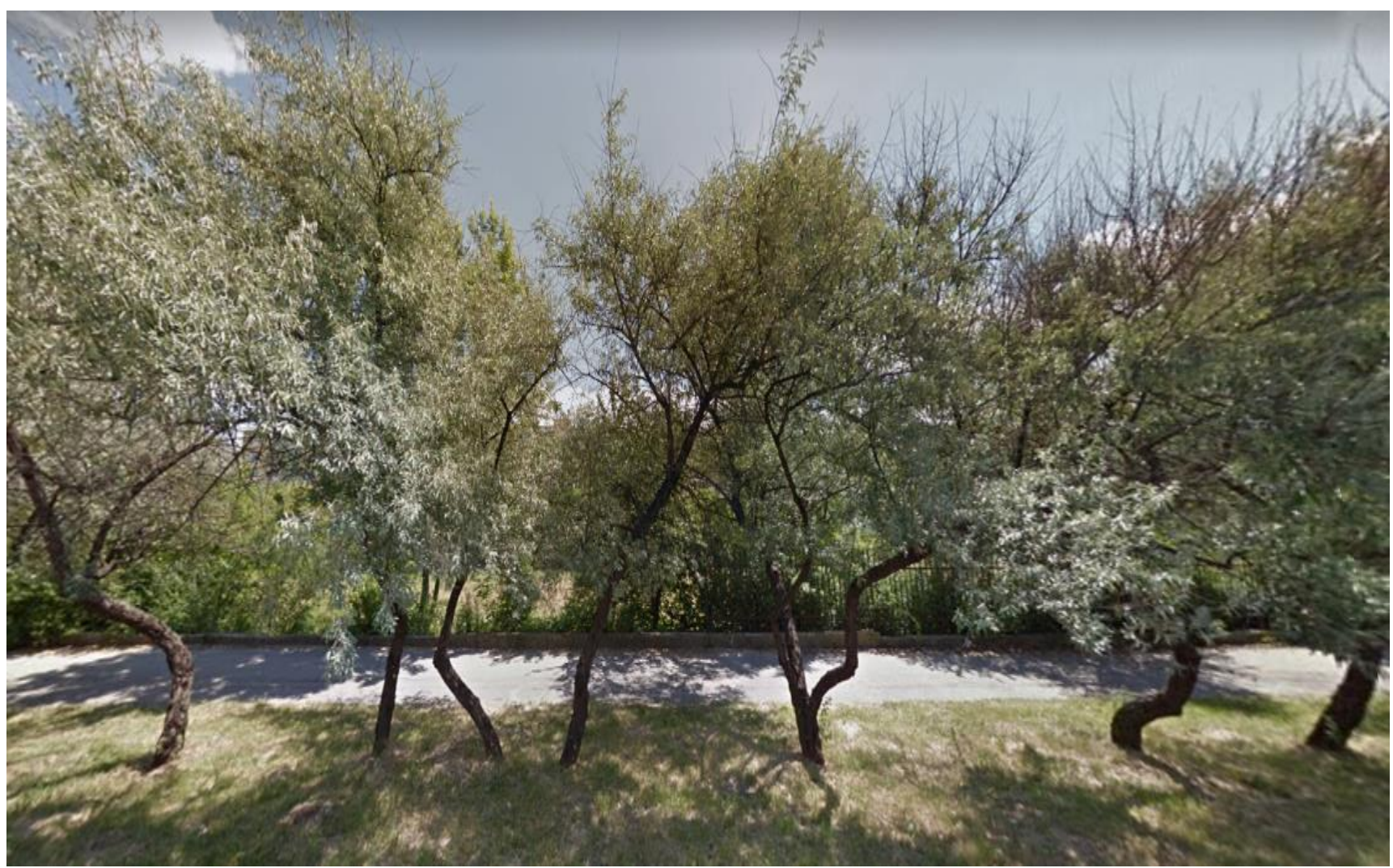

Figure 7. Tree growth anomaly

(Source: Own processing, Location: Kosice, Popradska street, Slovakia) 


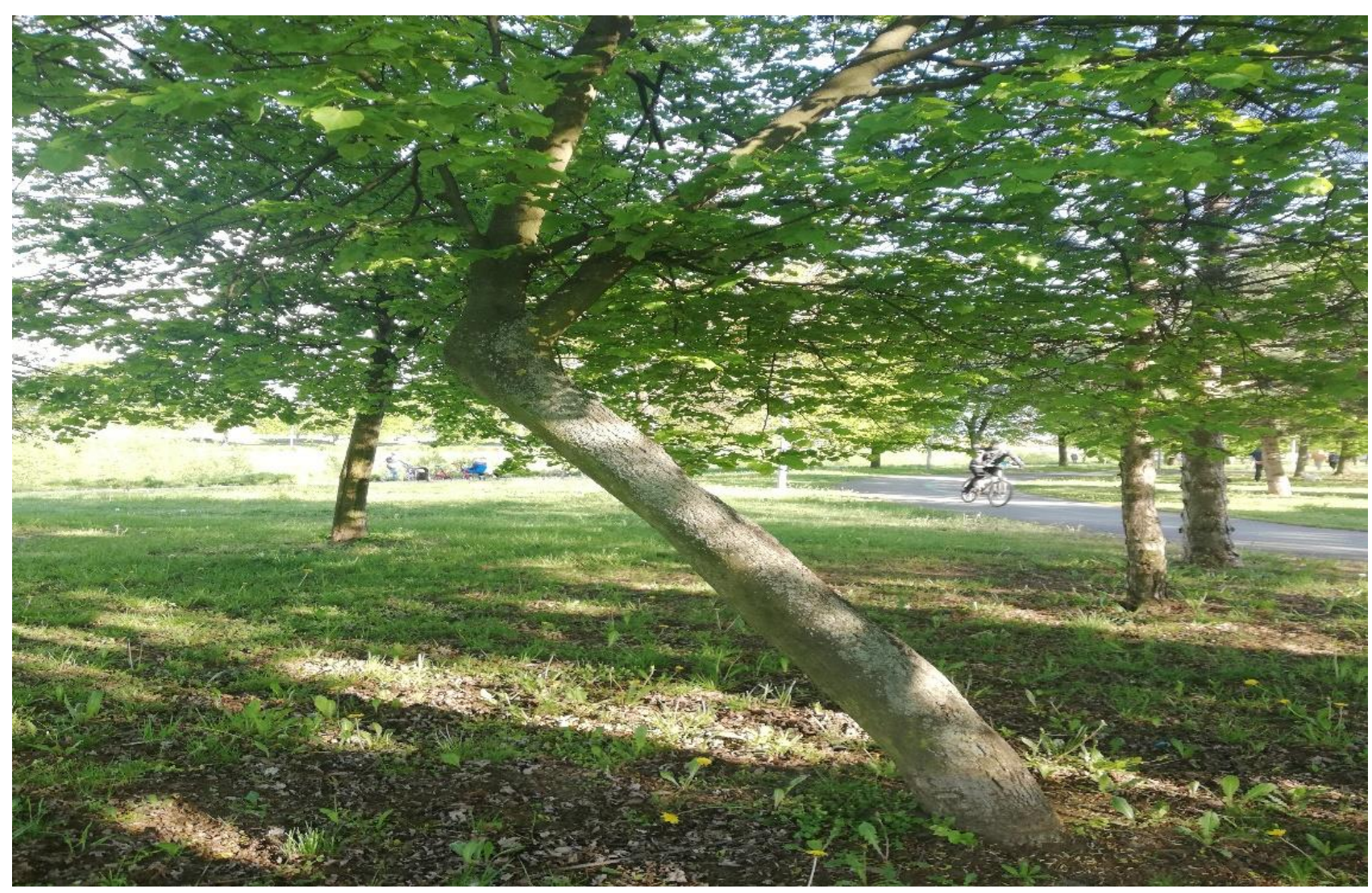

Figure 8. GPZ under the tree

(Source: Own processing, Location: Presov, Matica slovenskej street, Slovakia)

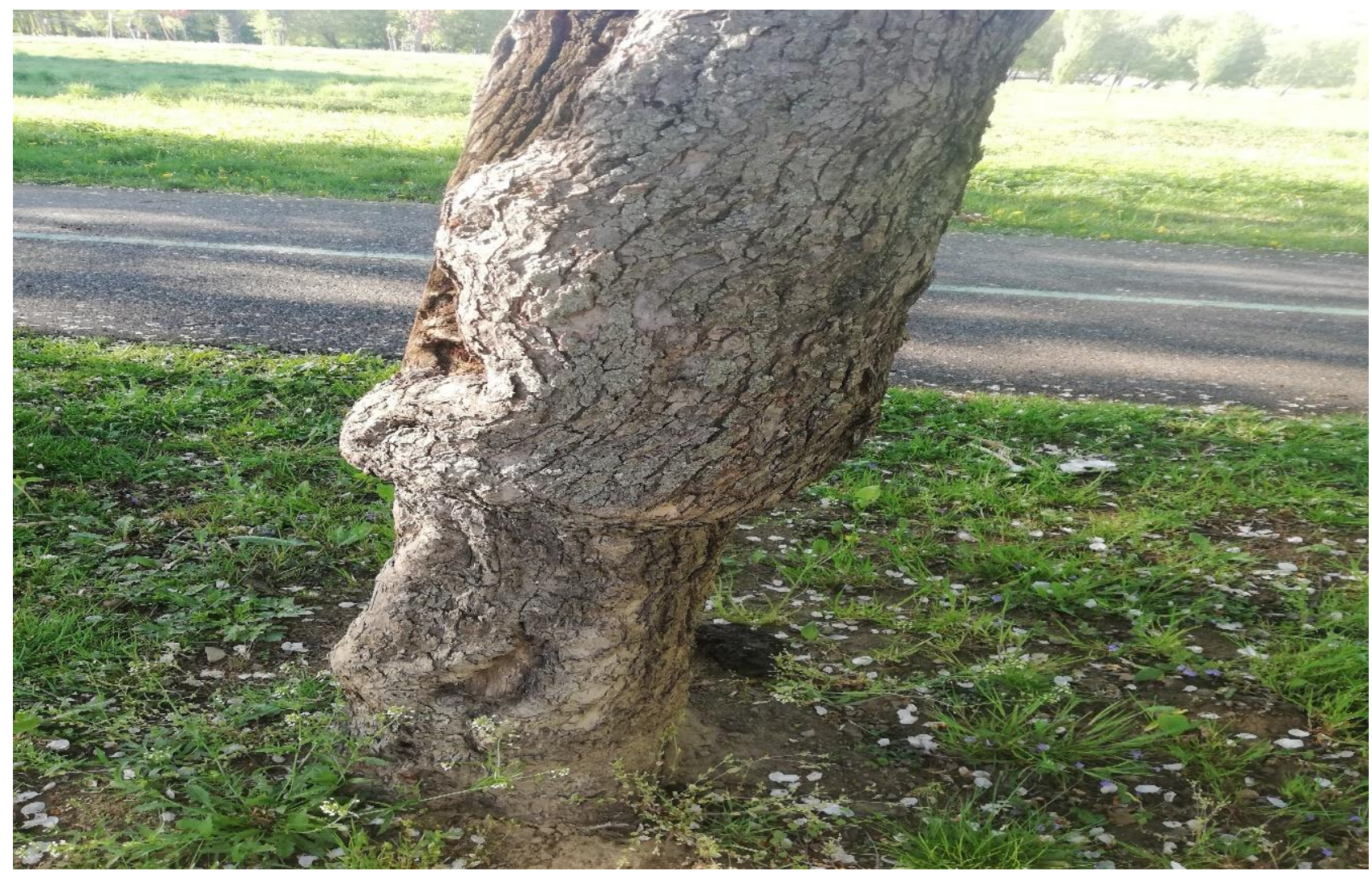

Figure 9. Pathogen on the tree trunk

(Source: Own processing, Location: Presov, Matica slovenskej street, Slovakia) 


\section{Conclusion}

Prolonged use of a mobile phone daily for several hours can cause the electromagnetic field to interact with the human body [12]. The position of the phone when charging is also important. It is best to charge the phone away from the head, preferably in another room rather than where we sleep. To eliminate these symptoms, we recommend using mobile phones or other electronic devices as little as possible. If this is not possible then, at least, take short breaks during use on an ongoing basis. Some people may interact so strongly that they may experience blurred vision, dizziness, or even vomiting. These symptoms are a manifestation of very strong and long-term electromagnetic radiation, but this was not observed in our respondents.

Dharmadhikari [25] stated what effect electronic devices have on the quality of our sleep. From the data we obtained from our participants, we found that most have no problem falling asleep. Some have trouble sleeping. There is no waking up during the night either. There was also no sleep problem with other household members. To increase quality of sleep, we recommend that you do not use electronic devices for at least 30 minutes before going to bed. Such use can interfere with the production of the hormone melatonin, which is very necessary for sleep. Do not leave the phone under the pillow during the night, where it interacts significantly with brain waves. It is best to put the electronic device in another room, turn off the mobile phone completely. The brain is active during the night, although not to the same extent as during the day, and each "flash" of the LED indicator on the electronic device causes a disruption of the sleep cycle.

In general, geopathogenic zones occur in places where there are various inhomogeneities in the earth's crust, or in various places where the soil composition changes, in old buried caves and also by the action of groundwater, as Aghav claims [26]. The radiation that radiates from the Earth can affect human beings to a very high degree. The most common symptom of finding out that we are in such a zone is that in certain places in the household where we are staying, we most often feel a certain unusual, unpleasant feeling. Hacker [30] argues that these feelings may not only be caused by geopathogenic zones, but also by the interaction of the electromagnetic field with the human body. No such places in the household where they feel discomfort were observed by our participants. The longer the organism or animal stays in such a zone, the greater the impact it can have on them. The longest above such zones can be trees or plants in general. By not making any movement, they stay above this zone all the time. Subsequently, growth anomalies occur, with various tumors on the tree trunk, as described in Chafekar [31]. Of course, how these zones affect us depends on their strength and intensity. Geopathogenic zones affect animals and flora. Using a questionnaire, we found out that near the homes of our participants there are trees that contain growth anomalies, as we can see in the Fig. 7, 8, and 9. These anomalies can be caused by GPZ, but further study of this problem is appropriate. Our respondents observed whether their pets have their favorite places to sleep. It turned out that animals like to look for mostly the same places to sleep. The most common pets such as dogs and cats are the best indicators for the theoretical localization of GPZ. In conclusion, our preliminary study showed, that it is necessary to count with GPZ as an objectively occurring phenomenon, which together with other environmental influences have an impact on organism. A person who is under the influence of increased exposure to various types of radiation does not feel well, he may feel tired, and can get sick from excessive influence. Several studies are needed in the future to fully demonstrate the occurrence of these zones. Localization of these zones isn't always easy. The electromagnetic field is part of our lives and it is up to us how to protect ourselves from it and use it wisely. Biomedicine is increasingly using EMP, but opponents of this energy are trying to prove that EMF is harmful. Much remains to be done to confirm some of the biological effects of EMF. Only years of research and operation of EMF in this technically advanced society will show what effects the electromagnetic field and GPZ will have on life.

\section{References}

[1] B. Sharma, S. Prasad, R. Pandey, J. Singh, K. S. Sodhi and D. Wadhwa, "Evaluation of Stress among Post-graduate Medical and Dental Students: A pilot study," Delhi Psychiatry Journal, vol. 16, no. 2, pp. 312-316, 2013.

[2] M. P. Hrebniak, O. V. Kirsanova, and V. V. Taranov, "Geopathogenic zones and oncological morbidity of the population," Zaporozhye Medical Journal, vol. 22, no. 6, pp. 811-815, 2020.

[3] D. Deming, "Water Witching and Dowsing1," Ground Water, vol. 40, no. 4, pp. 450-453, 2002.

[4] Agricola, G. De Re Metallica. Translated from the first Latin. 1556; edition by H. C. Hoover and L. H. Hoover. New York Dover Publications 1950. 
[5] C. Augner, G. W. Hacker, and I. Jekel, "Geopathic Stress Zones: Short-Term Effects on Work Performance and Well-Being?," The Journal of Alternative and Complementary Medicine, vol. 16, no. 6, pp. 657-661, 2010.

[6] A. Sandor, "Geopathogenic zone-the negative factor of the environment changes a radioactive radiation," 2000.

[7] R. Creightmore, "Geopathic stress. The geomancy group," 2012. [Online]. Available: http://www.safespace.net.nz/pdf/GEOPATHIC\%20STRESS\%20by\%20Richard\%20Creightmore.pdf [Accessed March 25, 2021].

[8] H. Jurgec, "Use of electronic instruments for detection of geopathogenic radiation," 2008.

[9] A. Stark, "Earth energies and geopathic stress," 2019. [Online]. Available: http://alexstark.com/pdfs/Geopathic\%20Stress.pdf [Accessed March 26, 2021].

[10] D. J. Croome, "The effect of geopathic stress on building occupants," Renewable Energy, vol. 5, no. 58, pp. 993-996, 1994.

[11] P. Dubrov, "Biological geophysics. Field. Earth. Man and the cosmos," 2009.

[12] Ch. Bird, "The divining hand: The 500 year-old mystery of dowsing," pp.340, 1979.

[13] M. Krinker and A. Goykadosh, "Mapping Geo-Pathogenic Zones and Required Instrumentatiol," Journal 2010 IEEE Long Island systems, applications and technology center, p. 1-4, 2010.

[14] T. Saunders, "Health hazards and electromagnetic fields," Journal of Complementary therapies in nursing and midwifery, vol.9, no. 4, pp.191-197, 2003.

[15] W. Hacker, et al., "Geopathic stress zones and their influence on the human organism," Journal of Proceedings of the congress on Earth's fields and their influence on human beings, pp. 8-17, 2008.

[16] K. Meyl, "Scalar waves. From an extended vortex and field theory to a technical, biological and historical use of longitudial waves," 2004.

[17] A. Dubrov, "Geopathic zones and oncological diseases," Journal of Proceedings of the sixteenth BDA congress on Earth's fields and their influence on human beings, pp. 42-44, 2008.

[18] Z. Matoušek, M. Šostronek and J. Jakub, "Vplyv elektromagnetického žiarenia mobilných telefónov na ludský organizmus," Journal of Výchova a vzdelávanie elektrotechnikov-EMC 2009. [Online]. Available: http://www. aos. sk/spe/seminare/SPE_2009/zbornik/07matousek_09. pdf [Accessed March $25,2021]$.

[19] O. Osina, "Mobilné telefóny, aktuálny problém súčasnosti," Journal of Nové poznatky v oblasti medicinskych vied a ošetrovatel'stva, Fakulta zdravotníctva Katolíckej univerzity, Ružomberok. 2006.

[20] A. W. Wood, S. P. Loughran, and C. Stough, "Does evening exposure to mobile phone radiation affect subsequent melatonin production?," International Journal of Radiation Biology, vol. 82, no. 2, pp. 6976, 2006.

[21] M. Hysing, "Sleep and use of electronic devices in adolescence: results from a large population-based study," 2015. [Online]. Available: https://bmjopen.bmj.com/content/bmjopen/5/1/e006748.full.pdf [Accessed March 28, 2021].

[22] S. Thomée, L. Dellve, A. Härenstam, and M. Hagberg, "Perceived connections between information and communication technology use and mental symptoms among young adults - a qualitative study," BMC Public Health, vol. 10, no. 1, 2010.

[23] G. Figueiro, "The impact of light from computer monitors on melatonin levels in college students," Journal of Neuroendocrinology letters, vol. 32, no.2, pp.158-163, 2011.

[24] J.Arendt, "Melatonin and the mammalian pineal gland chapman and hall," London, UK. 1995.

[25] N. Dharmadhikari, "Use of dowsing and geo-resistivity meter for detection of geopathic stress zone," International journal of modern engineering research, vol. 1, no. 2, pp.609-614, 2011.

[26] D. Aghav and P. Tambade, "Investigating effects of geopathic stress on health parameters in young healthy volunteers," International Journal of chemical and physical sciences, vol.4, pp. 29-34, 2015.

[27] V. A. Boltunov, V. V. Boltunov, "Nontraditional survey methods in hydrotechnical construction search for geopathogenic zones: biolocation and geophysics," Journal of Hydrotechnical construction, vol. 30, no.7, pp.425-433, 1996.

[28] D. Freshwater, "Geopathic stress," Journal of Complementary therapies in nursing and midwifery, vol. 3, no. 6, pp.160-162, 1997.

[29] L. Pekárek, M. Rojko, "Geopatogenní zóny a fyzika," Journal of Pokroky matematiky, fyziky a astronomie, vol. 36, no. 1, pp. 24-37, 1991. 
[30] G. W. Hacker, E. Pawlak, G. Pauser, G. Tichy, H. Jell, G. Posch, G. Kraibacher, A. Aigner, and J. Hutter, "Biomedical Evidence of Influence of Geopathic Zones on the Human Body: Scientifically Traceable Effects and Ways of Harmonization," Complementary Medicine Research, vol. 12, no. 6, pp. 315-327, 2005.

[31] H. Chafekar, P. Jarad, "Effect of Geopathic Stress on Pavement Distresses," Journal of Mechanical and Civil Engineering, pp. 1-8, 2012. 